OPEN ACCESS

Edited by:

Francesco Antonio Aprile, Imperial College London,

United Kingdom

Reviewed by:

Beat H. Meier,

ETH Zürich, Switzerland

Alfonso De Simone,

Imperial College London,

United Kingdom

*Correspondence:

Derek R. Dee

derek.dee@ubc.ca

Specialty section:

This article was submitted to

Structural Biology,

a section of the journa

Frontiers in Molecular Biosciences

Received: 04 May 2020

Accepted: 28 July 2020

Published: 14 August 2020

Citation:

Rahimi Araghi $L$ and Dee DR

(2020) Cross-Species

and Cross-Polymorph Seeding

of Lysozyme Amyloid Reveals

a Dominant Polymorph.

Front. Mol. Biosci. 7:206

doi: $10.3389 /$ fmolb.2020.00206

\section{Cross-Species and Cross-Polymorph Seeding of Lysozyme Amyloid Reveals a Dominant Polymorph}

\author{
Lida Rahimi Araghi' and Derek R. Dee ${ }^{2 *}$ \\ 'Department of Food Science and Technology, University of Georgia, Athens, GA, United States, ${ }^{2}$ Faculty of Land and Food \\ Systems, The University of British Columbia, Vancouver, BC, Canada
}

The ability to self-propagate is one of the most intriguing characteristics of amyloid fibrils, and is a feature of great interest both to stopping unwanted pathological amyloid, and for engineering functional amyloid as a useful nanomaterial. The sequence and structural tolerances for amyloid seeding are not well understood, particularly concerning the propagation of distinct fibril morphologies (polymorphs) across species. This study examined the seeding and cross-seeding reactions between two unique fibril polymorphs, one long and flexible (formed at $\mathrm{pH}$ 2) and the other short and rigid (formed at $\mathrm{pH}$ 6.3), of human lysozyme and hen egg-white lysozyme. Both polymorphs could cross-seed aggregation across species, but this reaction was markedly reduced under physiological conditions. For both species, the pH 6.3 fibril polymorph was dominant, seeding fibril growth with a faster growth rate constant at $\mathrm{pH} 2$ than the $\mathrm{pH} 2$ polymorph. Based on fibrillation kinetics and fibril morphology, we found that the $\mathrm{pH} 2$ polymorph was not able to faithfully replicate itself at $\mathrm{pH}$ 6.3. These results show that two distinct amyloid polymorphs are both capable of heterologous seeding across two species (human and hen) of lysozyme, but that the $\mathrm{pH} 6.3$ polymorph is favored, regardless of the species, likely due to a lower energy barrier, or faster configurational diffusion, to accessing this particular misfolded form. These findings contribute to our better understanding of amyloid strain propagation across species barriers.

Keywords: protein aggregation, amyloid strains, heterologous seeding, species barrier, amyloid growth kinetics, polymorphism, lysozyme

\section{INTRODUCTION}

Understanding the structure and assembly mechanisms of amyloid fibrils is of great interest owing to their broad importance. Amyloid fibrils are central to numerous pathologies (Chiti and Dobson, 2017), are increasingly being linked with native biological functions (Fowler et al., 2007; Maji et al., 2009; Liu et al., 2017), and are likely to find applications as biomaterials and devices (Knowles and Mezzenga, 2016). Much remains to be understood about how proteins change their folded structure, self-assemble into protofilaments, and how these (typically 2-6) further combine to form mature fibrils (Adamcik and Mezzenga, 2018).

A given protein can be induced to form distinct amyloid fibril strains, also termed polymorphs, that can differ in terms of core structure, morphology, stability, and cytotoxicity (Tycko, 2015; Adamcik and Mezzenga, 2018). Fibril polymorphs have been characterized for several proteins, 
including human lysozyme (HLZ) (Mossuto et al., 2010), hen egg-white lysozyme (HEWL) (Lara et al., 2011), insulin (Sneideris et al., 2015), $\alpha$-synuclein (Bousset et al., 2013), serum albumin (Usov et al., 2013), A $\beta_{1-40}$ (Petkova et al., 2005), and prion protein (Cobb et al., 2014). Amyloids obtained in vivo were found to be polymorphic (Annamalai et al., 2016) and amyloid polymorphism may underlie differences in pathological phenotypes (Peelaerts et al., 2015). Selection between polymorphs may be kinetically controlled, with differences in nucleation barriers determining which nuclei are dominant under a given set of conditions, leading to one polymorph being dominant (Pellarin et al., 2010). Fibril polymorphism is highly sensitive to environmental or chemical effects; this is perhaps best exemplified by the well-characterized $A \beta_{1-40}$ peptide that forms distinct polymorphs in response to shaking (striated ribbon fibrils) or not shaking (twisted ribbon fibrils) (Tycko, 2015). The arrangement of water molecules around oligomers and protofilaments during fibrillation could also affect polymorphism (Stephens and Kaminski Schierle, 2019).

In the nucleation-polymerization mechanism (Jarrett and Lansbury, 1993), fibrillation begins with nuclei formation, which strongly affects the lag-phase in the sigmoidal kinetics of fibril production. The lag-phase can be shortened by addition of preformed fibrils that act as "seeds." A protein may also be crossseeded (Morales et al., 2013) using fibril seeds derived from a similar protein that differs in sequence (e.g., mutants, or from a different species), or using a completely unrelated protein. Crossseeding may also refer to when fibrils grown under one set of conditions are used as seeds under a different set of conditions (e.g., polymorphic cross-seeding). Cross-seeding is relevant to species barriers in prion diseases (Collinge and Clarke, 2007), to co-aggregation of different proteins in neurodegenerative disease (Hashimoto et al., 2019), and should also be considered when assessing the safety of fibrils engineered for human use. Owing to their novel properties, there is interest in engineering amyloid fibrils for use in materials, devices (Knowles and Mezzenga, 2016), and food (Loveday et al., 2009; Mohammadian and Madadlou, 2018). For applications that may result in human exposure to engineered fibrils, it is prudent to examine their safety (Lasse et al., 2016). One concern is whether fibrils derived from other species may cross-seed amyloid formation of human proteins (Friedland and Chapman, 2017). Cross-seeding is generally inefficient for proteins of low sequence similarity (Krebs et al., 2004; Wright et al., 2005), although, there is evidence of cross-seeding between dissimilar proteins such as amyloid$\beta$ and human islet amyloid polypeptide, with $25 \%$ sequence identity (Zhang et al., 2015), and curli protein and prostate acid phosphatase (Hartman et al., 2013).

Lysozyme is a well studied model of amyloid formation and numerous methods are known to induce lysozyme fibrillogenesis (Trexler and Nilsson, 2007; Swaminathan et al., 2011). Lysozyme fibrillation can be induced using $\mathrm{pH} 2$ and elevated temperatures $\left(37-90^{\circ} \mathrm{C}\right)$, which results in extensive (Frare et al., 2004; Lara et al., 2011) to limited (Arnaudov and de Vries, 2005; Frare et al., 2006) or no (Krebs et al., 2000; Mossuto et al., 2010) hydrolysis of the fibrillar protein, depending on the particular conditions. Alternatively, a less well-characterized method is to use $3 \mathrm{M}$ guanidine hydrochloride $(\mathrm{GdnHCl})$ at $\mathrm{pH} 6.3$ and $45-50^{\circ} \mathrm{C}$ (Vernaglia et al., 2004) or $3 \mathrm{M} \mathrm{GdnHCl}$ at $\mathrm{pH} 7$ and $57^{\circ} \mathrm{C}$ (Sulatskaya et al., 2017). Previous studies looked at various seeding and cross-seeding reactions of lysozyme fibrils (Krebs et al., 2000, 2004; Vernaglia et al., 2004; Buell et al., 2011; Mulaj et al., 2014). The efficiency of cross-seeding HEWL decreased with the sequence identity of the seed protein: turkey (95\% identity) and human (60\% identity) lysozyme seeds were equally (turkey) or intermediately (human) effective as HEWL seeds, while $\alpha$-lactalbumin (36\% identity) and bovine insulin (no identity) fibrils were ineffective as seeds (Krebs et al., 2004). In turn, HEWL fibrils were able to seed fibrillation of turkey lysozyme but not human $\alpha$-lactalbumin (Krebs et al., 2004).

Here, we examined seeding across both species (HEWL and HLZ) and fibril polymorphs, to examine their influence on nucleation barriers and fibril growth. We compared two polymorphs, one formed at $\mathrm{pH} 2$ and one formed at $\mathrm{pH} 6.3$ with $3 \mathrm{M} \mathrm{GdnHCl}$. Based on previous studies (Frare et al., 2004; Vernaglia et al., 2004), we anticipated that fibrils grown under these conditions would differ in terms of morphology (length, stiffness, protofilament assembly) and molecular structure, with hydrolysis likely to occur at $\mathrm{pH} 2$ giving rise to a unique surface chemistry. We show that the $\mathrm{pH} 2$ and $\mathrm{pH} 6.3$ fibril polymorphs of lysozyme differ greatly in their morphology and cross-seeding behavior, with the $\mathrm{pH} 6.3$ polymorph propagating more quickly even at low $\mathrm{pH}$ and absent of chemical denaturant. The fibrillar proteins are extensively hydrolyzed at $\mathrm{pH} 2$, but remain intact at $\mathrm{pH}$ 6.3. The fibrils formed at $\mathrm{pH} 6.3$ undergo cleavage at $\mathrm{pH} 2$, yet the fibrils remain intact and able to propagate their distinct morphology.

\section{MATERIALS AND METHODS}

\section{Materials}

Hen egg-white lysozyme (L6876), HLZ (L1667), porcine pepsin (P6887), and Thioflavin T (ThT, T3516), were purchased from Sigma-Aldrich (United States). GdnHCl, was purchased from Fisher (United States). Uranyl acetate and 0.5\% formvar solution were purchased from Electron Microscopy (United States). All buffers and solutions were prepared using ultra-pure water (Purelab Ultra, ELGA, United Kingdom).

\section{Preparation of Fibrils and Seeds}

Lysozyme solutions were prepared by mass, centrifuged at $7,800 \mathrm{rcf}$ for $20 \mathrm{~min}$ and filtered $(0.22 \mu \mathrm{m})$ to remove any insoluble protein. Protein concentration was determined by absorbance at $280 \mathrm{~nm}$, measured using a NanoDrop One UVVis spectrophotometer (Thermo Scientific, United States), using extinction coefficients of 37,970 and $36,940 \mathrm{M}^{-1} \mathrm{~cm}^{-1}$ for HEWL and HLZ, respectively.

Fibrillation was induced by incubating $1 \mathrm{mM}$ protein solutions, with constant shaking at $300 \mathrm{rpm}$, in either $50 \mathrm{mM}$ Glycine- $\mathrm{HCl}, \mathrm{pH} 2.0$, at $65^{\circ} \mathrm{C}$, or in $20 \mathrm{mM}$ potassium phosphate, $\mathrm{pH} 6.3$, containing $3 \mathrm{M} \mathrm{GdnHCl}$, at $50^{\circ} \mathrm{C}$. The $\mathrm{GdnHCl}$ concentration was determined using refractive index (Pace, 1986). The $\mathrm{pH} 2.0$ samples were incubated for 7 days, and 
the $\mathrm{pH} 6.3$ samples were incubated for 3 days. Mature fibrils were sonicated at room temperature using a Vibra-Cell VC-50 ultrasonic processor fitted with a flat $2 \mathrm{~mm}$ titanium microtip probe (Sonics \& Materials Inc., United States). The instrument was operated at $20 \mathrm{kHz}$ frequency and the power was set to $40 \%$ ultrasonic amplitude. Samples were placed in an ice bath and were sonicated for three $10 \mathrm{~s}$ pulses, with a $5 \mathrm{~s}$ rest in between each pulse.

\section{Fibrillation Kinetics}

Experiments were conducted using black, clear-bottom, 96well microplates (Greiner Bio-One, United States). Fibril seeds $(0.1 \mathrm{mg} / \mathrm{ml}$ final concentration) were added to freshly prepared native protein solutions $(2 \mathrm{mg} / \mathrm{ml})$ in a total volume of $200 \mu \mathrm{L}$. $20 \mu \mathrm{M}$ ThT was included for fluorescence measurements. The microplates were sealed with a black plastic film (Perkin Elmer, United States), incubated at $45^{\circ} \mathrm{C}$ with $20 \mathrm{~s}$ of shaking every $10 \mathrm{~min}$. Fluorescence was measured using a SpectraMax Gemini EM spectrofluorophotometer (Molecular Devices, United States), in bottom-reading mode with excitation at $440 \mathrm{~nm}$ and emission at $486 \mathrm{~nm}$. The resulting traces of fluorescence intensity $(I)$ over time $(t)$ were fit using the equation (Arosio et al., 2015):

$$
I=I_{0}+A /\left(1+\exp \left(-k\left(t-t_{0.5}\right)\right)\right)
$$

where $I_{0}$ is the pre-transition baseline, $A$ is the transition amplitude, $k$ is the apparent rate constant for fibril growth, and $t_{0.5}$ is the transition half-time. The lag-time was derived from $t_{\text {lag }}=t_{0.5}-1 / 2 \mathrm{k}$.

\section{TEM}

Samples for TEM were diluted in MilliQ water $(200 \mu \mathrm{g} / \mathrm{mL}$ protein concentration), and $5 \mu \mathrm{L}$ was placed on 200-mesh copper formvar/carbon-coated grids (Ted Pella, Inc., United States). After $5 \mathrm{~min}$ the grids were rinsed three times with $5 \mu \mathrm{L}$ ultrapure water, with the excess water removed by blotting with filter paper. Next, $5 \mu \mathrm{L}$ of $2 \%$ (w/v) uranyl acetate solution was placed on the grid, and after $30 \mathrm{~s}$ the excess was removed using filter paper and the grids were dried at room temperature. Analysis was performed using a JEOL JEM1011 microscope (JEOL, Inc., United States) at the Georgia Electron Microscopy facility, University of Georgia. Images were analyzed using ImageJ.

\section{SDS-PAGE}

Fibrils were isolated using a $50 \mathrm{kDa}$ spin filter, then diluted with an equivalent volume of tricine sample buffer containing $2 \%$ $\beta$-mercaptoethanol, and heated at $95^{\circ} \mathrm{C}$ for $5 \mathrm{~min}$. Samples were run on $16.5 \%$ tris-tricine Mini-Protean precast gels (Bio-Rad, United States) at $100 \mathrm{~V}$. Afterward, gels were placed in a fixative solution ( $40 \%$ methanol, and $10 \%$ acetic acid) for $30 \mathrm{~min}$, stained for $1 \mathrm{~h}(0.025 \% \mathrm{w} / \mathrm{v}$ Coomassie blue G-250, 10\% acetic acid), and then destained in $10 \%$ acetic acid solution.

\section{Mass Spectrometry}

Fibrils were isolated using a $50 \mathrm{kDa}$ spin filter, then analyzed by MALDI-TOF using a Bruker Autoflex time-of-flight (TOF) mass spectrometer at the Proteomics and Mass Spectrometry facility, University of Georgia.

\section{Pepsin Treatment}

Fibril samples $(2 \mathrm{mg} / \mathrm{ml})$ were treated with $0.5 \mathrm{mg} / \mathrm{ml}$ porcine pepsin $(\sim 1900 \mathrm{U} / \mathrm{ml})$ at $\mathrm{pH} 2,37^{\circ} \mathrm{C}$, for $24 \mathrm{~h}$, and then analyzed by ThT fluorescence and TEM. Crossseeding experiments were also conducted under simulated gastric conditions, with $0.5 \mathrm{mg} / \mathrm{ml}$ pepsin, $\mathrm{pH} 1.2,34 \mathrm{mM} \mathrm{NaCl}, 37^{\circ} \mathrm{C}$ (simulated gastric fluid).

\section{RESULTS}

\section{Formation of Distinct Fibril Polymorph Seeds}

Hen egg-white lysozyme and HLZ fibril formation was carried out under two different conditions that resulted in two distinct fibril polymorphs (Figure 1). Treating both HEWL and HLZ with $\mathrm{pH} 2,65^{\circ} \mathrm{C}$ and agitation, resulted in the formation of relatively long, flexible fibrils. Treating the proteins with $\mathrm{pH} 6.3$, $3 \mathrm{M} \mathrm{GdnHCl}, 50^{\circ} \mathrm{C}$ with agitation resulted in relatively short, straight fibrils, that often displayed a twisted structure and lateral association. Following the kinetics of fibril formation using ThT (Figure 2) revealed that fibrillation was complete by 6 days at $\mathrm{pH}$ 2 and by 3 days at $\mathrm{pH}$ 6.3, for both HEWL and HLZ. Subsequent analysis by SDS-PAGE (Figure 2E) and MALDI-TOF (see below) revealed that extensive hydrolysis occurred at $\mathrm{pH} 2$, with the $\mathrm{pH}$ 2 fibrils comprised of intact and fragmented protein, while the fibrils at $\mathrm{pH} 6.3$ contained full-length protein. Mature fibrils were converted into "seeds" using sonication to break the fibrils down into shorter segments ( $\sim 200 \mathrm{~nm}$, Figures 1E,F) generating more fibril ends to serve as the fibril nucleation sites.

\section{Kinetics of Amyloid Formation}

Four different seed-types were obtained: HEWL seeds at $\mathrm{pH}$ 2 (HEWL2 $\mathrm{S}$ ) and $\mathrm{pH} 6.3$ (HEWL6.3s), and HLZ seeds at $\mathrm{pH}$ $2\left(\mathrm{HLZ}_{\mathrm{S}}\right)$ and $\mathrm{pH} 6.3$ (HLZ6.3S). Given the large number of samples (four seeds and the unseeded reaction for each condition), a microplate reader-based assay was used to follow the fibrillation kinetics in real-time, where the temperature was limited to $45^{\circ} \mathrm{C}$. The kinetics of fibril formation were compared for unseeded (U), seeded (S), cross-species seeded (XS), cross-polymorph seeded (PS), and cross-species-crosspolymorph seeded (XSPS) reactions using ThT fluorescence (Figure 3). The ThT data were fit according to a generic model (Eq. 1), and the fit results are given in Table 1. A number of different effects were observed. Polymorph effect ( $p H 2$ vs. 6.3) Fibril formation under both conditions, at $\mathrm{pH} 2$ and $\mathrm{pH}$ 6.3 with $3 \mathrm{M} \mathrm{GdnHCl}$, displayed the characteristic sigmoidal growth kinetics with an extended lag-phase followed by an exponential growth and then plateau in the ThT fluorescence intensity (Figure 3). In the absence of seeds, fibrillation at $\mathrm{pH} 6.3$ proceeded with much faster growth rates and shorter lag-times than at $\mathrm{pH}$ 2. Species effect (HEWL vs. HLZ) Compared to HLZ, fibrillation of HEWL was characterized by a much shorter lagtime yet similar growth rate at $\mathrm{pH} 2$; at $\mathrm{pH} 6.3$, their lag-times were similar yet HEWL had double the growth rate. Seeding effect As a nucleation-dependent process, fibrillation typically involves 


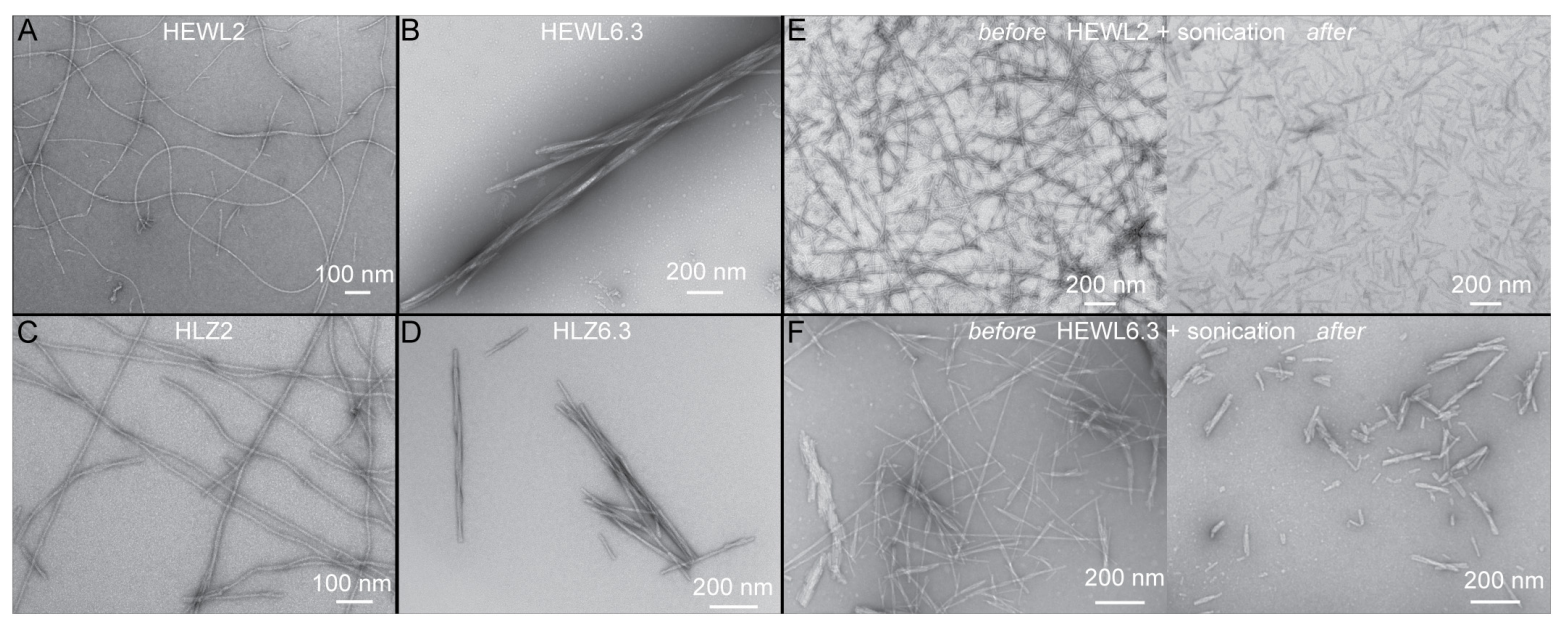

FIGURE 1 | Observation of distinct polymorphs using TEM. Distinct polymorphs of HEWL formed at (A) pH 2, and (B) pH 6.3. Distinct polymorphs of HLZ formed at (C) $\mathrm{pH}$ 2, and (D) pH 6.3. Panels (E,F) show before (left) and after (right) sonication of HEWL mature fibrils to create seeds at pH 2 (E) and pH 6.3 (F).

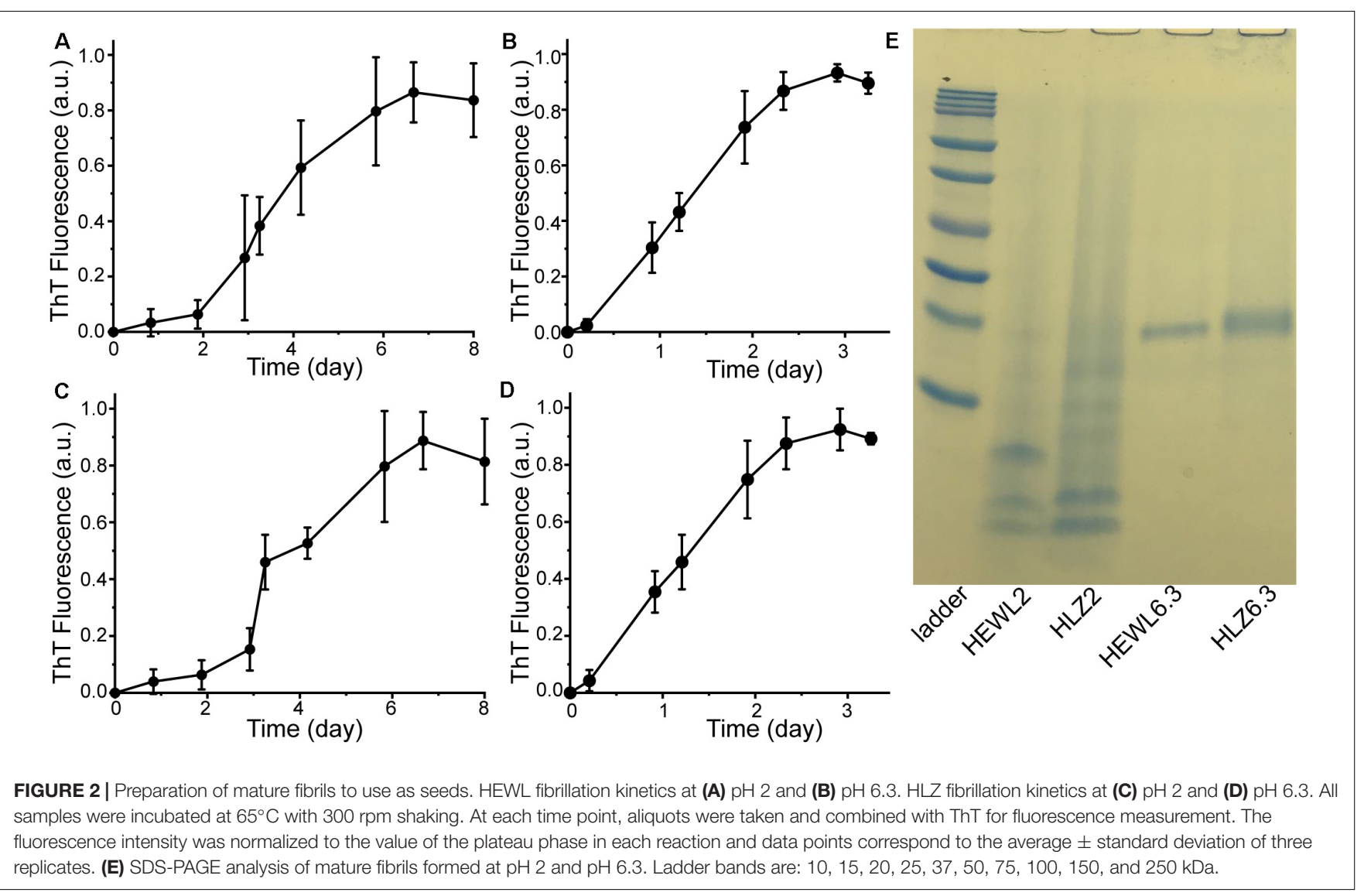

a lag-phase during which sufficient nucleation sites form. This lag-phase can be reduced or eliminated by adding pre-formed fibrils to act as seeds. Here, HEWL2s and HEWL6.3s decreased the fibrillation lag-time by a factor of $\sim 10$, while affecting the growth rate by a factor of only two-three (Table 1). Conversely, HLZ6.3s moderately shifted the lag-time lower (two-fold), while
HLZ2 ${ }_{S}$ was essentially ineffective as a seed (less than two-fold reduction in lag-time). XS effect HLZ2s was also ineffective at cross-seeding HEWL. Conversely, HEWL2s cross-seeded HLZ, decreasing the lag-time and increasing the growth rate by factors of four. No cross-seeding effect was observed for HEWL6.3s, while HLZ6.3s did lower the lag-time for HEWL6.3 by nearly 

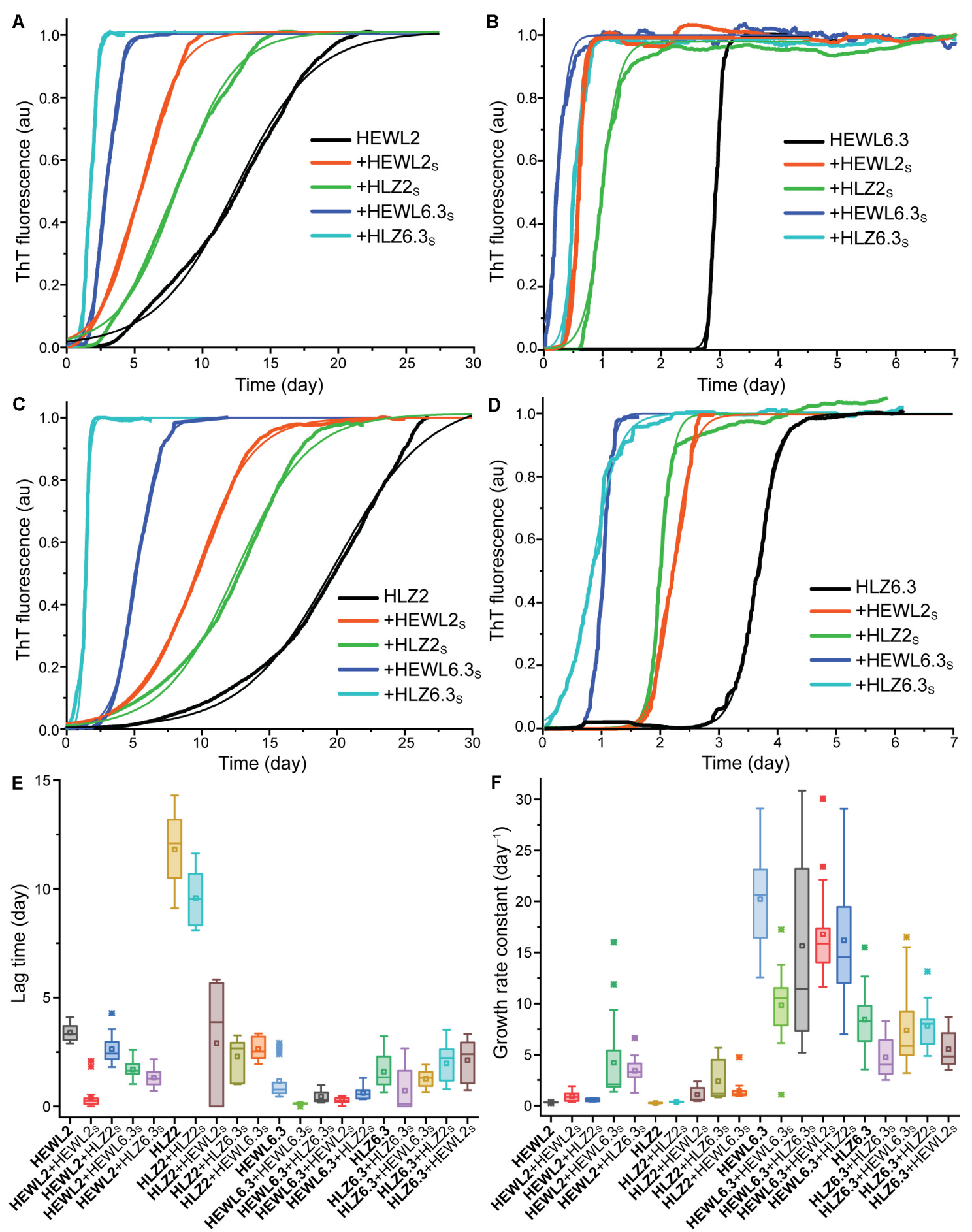

FIGURE 3 | Kinetics of amyloid formation. HEWL at (A) pH 2 and (B) pH 6.3. $\mathrm{HLZ}$ at (C) $\mathrm{pH} 2$ and (D) $\mathrm{pH}$ 6.3. Reactions occurred at $45^{\circ} \mathrm{C}$ in a microplate reader with intermittent shaking. The seeded reactions are indicated by ' + ' and the seed-type. Representative traces of ThT fluorescence (normalized to the maximum value) are shown, fitted with Eq. 1. Boxplots are shown for (E) lag-times and (F) growth rate constants, determined by fitting the data to Eq. 1. From left to right, the samples are arranged from unseeded, seeded, cross-seeded, cross-polymorph seeded, to cross-species-cross-polymorph seeded.

three-fold. PS effect Perhaps the most striking effect on fibrillation kinetics was observed when using the $\mathrm{pH} 6.3$ seeds at $\mathrm{pH} 2$. HEWL6.3s marginally reduced the lag-time (factor of two) but increased the growth rate constant 13-fold. HLZ6.3s reduced the lag-time by a factor of five and increased the growth rate constant nine-fold. In contrast, HEWL2S and HLZ2S had no 
TABLE 1 | Kinetic parameters of fibril formation.

\begin{tabular}{|c|c|c|c|c|c|c|c|}
\hline Reaction Type & Sample & Seed & Lag-time (day) & Factor decrease & Half-time (day) & Rate constant (day $\left.{ }^{-1}\right)$ & Factor increase \\
\hline S & HEWL 2 & HEWL2s & $0.39 \pm 0.12$ & 9 & $2.90 \pm 0.26$ & $0.91 \pm 0.10$ & 3 \\
\hline PS & HEWL 2 & HEWL6.3s & $1.70 \pm 0.09$ & 2 & $2.85 \pm 0.17$ & $4.21 \pm 0.94$ & 13 \\
\hline XSPS & HEWL 2 & HLZ6.3S & $1.32 \pm 0.10$ & 2.6 & $2.26 \pm 0.10$ & $3.42 \pm 0.31$ & 10 \\
\hline U & HLZ 2 & - & $11.82 \pm 0.52$ & & $19.53 \pm 0.18$ & $0.27 \pm 0.01$ & \\
\hline XS & HLZ 2 & HEWL2S & $2.91 \pm 1.01$ & 4 & $5.59 \pm 1.32$ & $1.09 \pm 0.20$ & 4 \\
\hline PS & HLZ 2 & HLZ6.3S & $2.30 \pm 0.21$ & 5 & $3.99 \pm 0.44$ & $2.38 \pm 0.47$ & 9 \\
\hline XSPS & HLZ 2 & HEWL6.3S & $2.65 \pm 0.12$ & 4 & $4.54 \pm 0.21$ & $1.45 \pm 0.22$ & 5 \\
\hline U & HEWL 6.3 & - & $1.16 \pm 0.17$ & & $1.29 \pm 0.17$ & $20.22 \pm 0.97$ & \\
\hline$S$ & HEWL 6.3 & HEWL6.3s & $0.12 \pm 0.01$ & 10 & $0.36 \pm 0.02$ & $9.84 \pm 0.81$ & 0.5 \\
\hline XS & HEWL 6.3 & HLZ6.3s & $0.45 \pm 0.06$ & 2.6 & $0.69 \pm 0.04$ & $15.65 \pm 2.25$ & 0.8 \\
\hline$S$ & HLZ 6.3 & HLZ6.3s & $0.73 \pm 0.31$ & 2.2 & $1.36 \pm 0.20$ & $4.72 \pm 0.53$ & 0.6 \\
\hline XS & HLZ 6.3 & HEWL6.3. & $1.27 \pm 0.10$ & 1.3 & $1.68 \pm 0.13$ & $7.38 \pm 1.07$ & 1 \\
\hline PS & HLZ 6.3 & HLZ2S & $1.98 \pm 0.22$ & 0.8 & $2.31 \pm 0.22$ & $7.82 \pm 0.50$ & 1 \\
\hline XSPS & HLZ 6.3 & HEWL2S & $2.13 \pm 0.24$ & 0.8 & $2.60 \pm 0.25$ & $5.53 \pm 0.45$ & 0.7 \\
\hline
\end{tabular}

Samples correspond to unseeded (U), seeded (S), cross-species seeded (XS), cross-polymorph seeded (PS), and cross-species-cross-polymorph seeded (XSPS) reactions. Data were obtained by fitting individual ThT kinetic traces with Eq. 1 and represent the mean \pm SEM of 11-25 replicates.

effect on the growth rate at $\mathrm{pH} 6.3$, although $\mathrm{HEWL} 2_{\mathrm{S}}$ did reduce the lag-time by a factor of four. XSPS effect The polymorph effect was also dominant when seeding across species. HEWL6.3S nucleated the fibrillation of HLZ at $\mathrm{pH} 2$ with a five-fold reduced lag-time and a five-fold increased growth rate. HLZ6.3s seeded HEWL2 with nearly a three-fold lower lag-time and a 10-fold higher growth rate. By comparison, the $\mathrm{pH} 2$ seeds, HEWL2S and $\mathrm{HLZ}_{\mathrm{S}}$, had little effect on fibrillation of HLZ and HEWL, respectively, at $\mathrm{pH} 6.3$.

Overall, there was a striking effect of species on seeding ability of the fibrils made at $\mathrm{pH}$ 2: while the HEWL fibrils made at $\mathrm{pH}$ 2 (HEWL2S) served as effective seeds, cross-species seeds, and cross-polymorph seeds, the HLZ2 $\mathrm{s}$ had little observed effect on the fibrillation kinetics under the conditions tested. However, both HEWL and HLZ fibrils made at pH 6.3 served as excellent seeds in the PS and XSPS reactions at $\mathrm{pH} 2$.

\section{Structure of Seeded Fibrils}

Human lysozyme fibrils that resulted from the various types of seeding reactions ( $\mathrm{S}, \mathrm{XS}$, PS, or XSPS) were analyzed by TEM to determine if the $\mathrm{pH} 2$ and $\mathrm{pH} 6.3$ seeds faithfully propagated their distinct morphology (Figure 4). Monomeric HLZ, at $\mathrm{pH} 2$, seeded with HLZ2 ${ }_{\mathrm{S}}$ or cross-seeded with HEWL2S produced long, flexible fibrils (Figures $4 \mathbf{A}, \mathbf{B}$ ) that looked identical to those produced during the unseeded reactions (Figures 1A,C). HLZ, at pH 2, cross-polymorph seeded with HLZ6.3S or cross-species-cross-polymorph seeded with HEWL6.3s, produced fibrils that were shorter and straighter (more rigid) (Figures 4C,D), being more similar to the unseeded fibrils produced at $\mathrm{pH} 6.3$ (Figures 1B,D). Treating monomeric HLZ, at $\mathrm{pH} 6.3$, with HLZ2s or HEWL2s, also produced short, rigid fibrils (Figures 4E,F) similar to the unseeded fibrils at $\mathrm{pH} 6.3$ (Figures 1B,D). These results indicated that the $\mathrm{pH} 6.3$ polymorphs (HLZ6.3S and HEWL6.3s) were able to faithfully propagate at $\mathrm{pH} 2$ in the absence of $3 \mathrm{M} \mathrm{GdnHCl}$, while the $\mathrm{pH} 2$ polymorphs were not able to replicate under the $\mathrm{pH} 6.3$ condition. Together with the kinetic results from ThT fluorescence, the TEM structures support that the $\mathrm{pH} 6.3$ polymorph is dominant and favored over the $\mathrm{pH} 2$ polymorph under both conditions of $\mathrm{pH} 2$ and $\mathrm{pH} 6.3$.

\section{Effect of Low pH and Simulated Gastric Conditions on Fibril Structure}

The $\mathrm{pH}$ stability of the $\mathrm{pH} 6.3$ polymorphs was examined by incubating mature HEWL6.3 and HLZ6.3 fibrils at $\mathrm{pH} 2,65^{\circ} \mathrm{C}$, with shaking at $300 \mathrm{rpm}$, for $24 \mathrm{~h}$. Analysis by TEM and MALDITOF (Figure 5) showed that the fibril morphology remained intact, even though the proteins underwent hydrolysis and the fibrils contained substantial fragmented protein after incubation at $\mathrm{pH}$ 2. MALDI-TOF results (Figure 5C) confirmed the SDS results (Figure 2E), indicating that fibrils made at $\mathrm{pH} 2$ and pH 6.3 differed in composition. The $\mathrm{pH} 2$ polymorph consisted of intact and hydrolyzed protein, while the $\mathrm{pH} 6.3$ polymorph contained only intact lysozyme. HEWL and HLZ are 14.3 and $14.7 \mathrm{kDa}$, respectively, and no bands at higher $\mathrm{Mw}$ were observed by SDS-PAGE (Figure 2E), suggesting that fibril formation involved only non-covalent bonds, which were broken down by heating in the presence of SDS (Arnaudov and de Vries, 2005).

Having observed lysozyme cross-seeding at $\mathrm{pH} 2,45^{\circ} \mathrm{C}$, we next examined whether seeding across species and polymorphs would occur under more physiological conditions, in simulated 


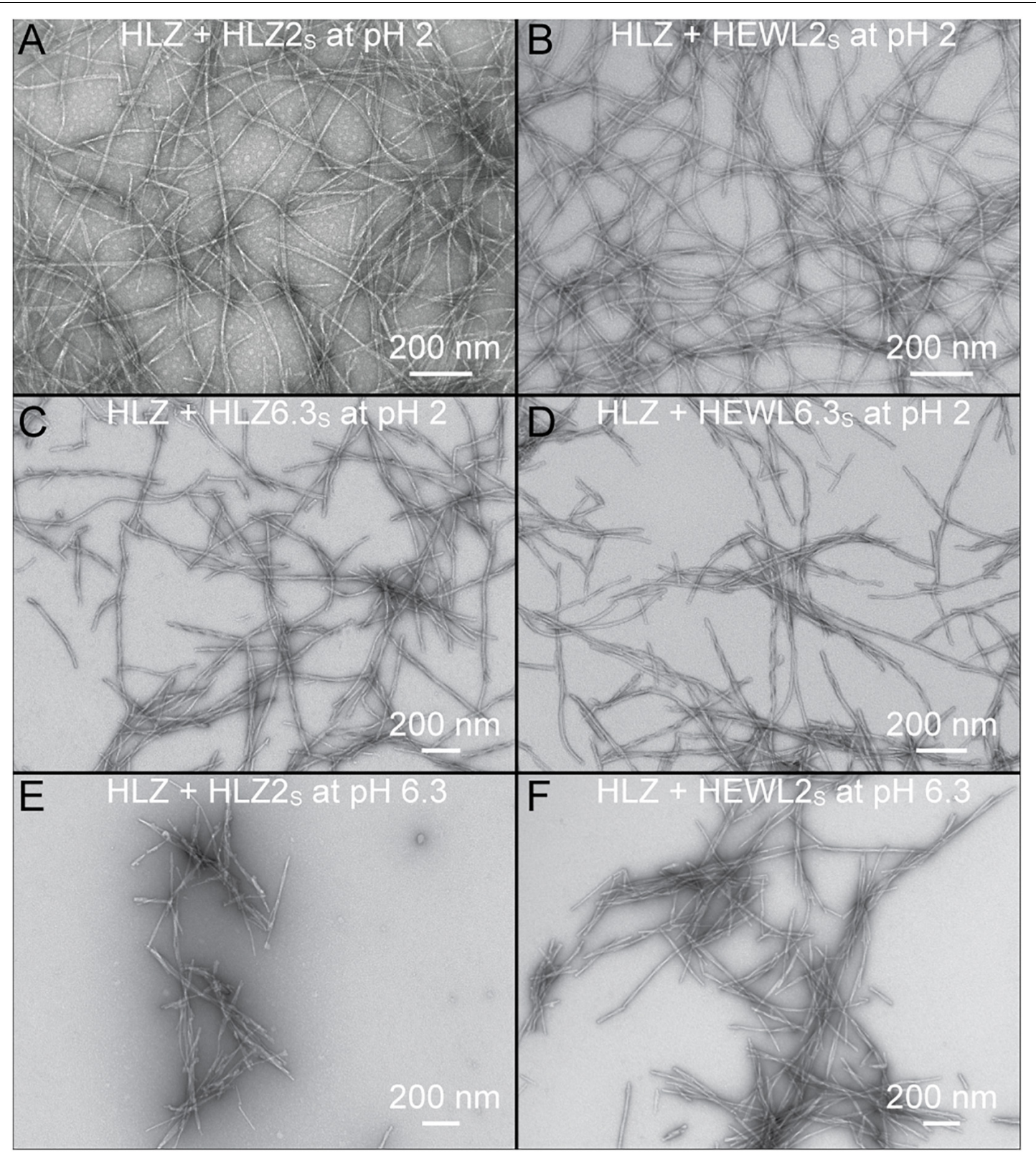

FIGURE 4 | Morphology of HLZ amyloid fibrils produced using various seeds and different conditions. (A) HLZ seeded with $H L Z 2$ s at pH 2. (B) HLZ cross-seeded with HEWL2s at pH 2. (C) HLZ cross-polymorph seeded with HLZ6.3s at pH 2. (D) HLZ cross-species-cross-polymorph seeded with HEWL6.3s at pH 2. (E) HLZ cross-polymorph seeded with HLZ2s at pH 6.3 with $3 \mathrm{M} \mathrm{GdnHCl}$ (F) HLZ cross-species-cross-polymorph seeded with HEWL2s at pH 6.3 with 3 M GdnHCl.

gastric fluid. HLZ monomers were incubated with various HEWL fibrils (HEWL6.3 pre-treated with pepsin, and HEWL6.3 and HEWL2 sonicated fibrils) in simulated gastric fluid and monitored using ThT fluorescence (Figure 5E). Within a period of 4 days, only one out of 36 samples formed fibrils under simulated gastric conditions, corresponding to one of $12 \mathrm{HLZ}$ samples that was seeded with HEWL6.3 fibrils pre-treated with $0.5 \mathrm{mg} / \mathrm{mL}$ pepsin. To examine whether the fibrils were resistant to pepsin treatment, HEWL6.3 fibrils were incubated for $24 \mathrm{~h}$ with pepsin $\left(2000 \mathrm{U} / \mathrm{ml}, \mathrm{pH} 2,37^{\circ} \mathrm{C}\right)$. There were no major changes in HEWL6.3 fibril structure after pepsin treatment
(Figure 5D), indicating that the fibril core was resistant to pepsin digestion.

\section{DISCUSSION}

\section{Polymorph Fidelity Under Different Conditions}

Lysozyme fibrils were produced under two conditions to yield distinct polymorphs: one at low $\mathrm{pH}$ with heating ("pH 2 fibrils") and the other at $\mathrm{pH} 6.3$ with $3 \mathrm{M} \mathrm{GdnHCl}$ ("pH 6.3 fibrils"). 
A

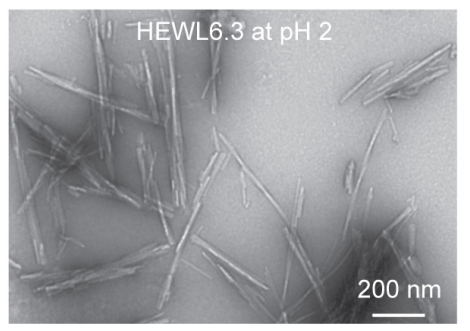

C

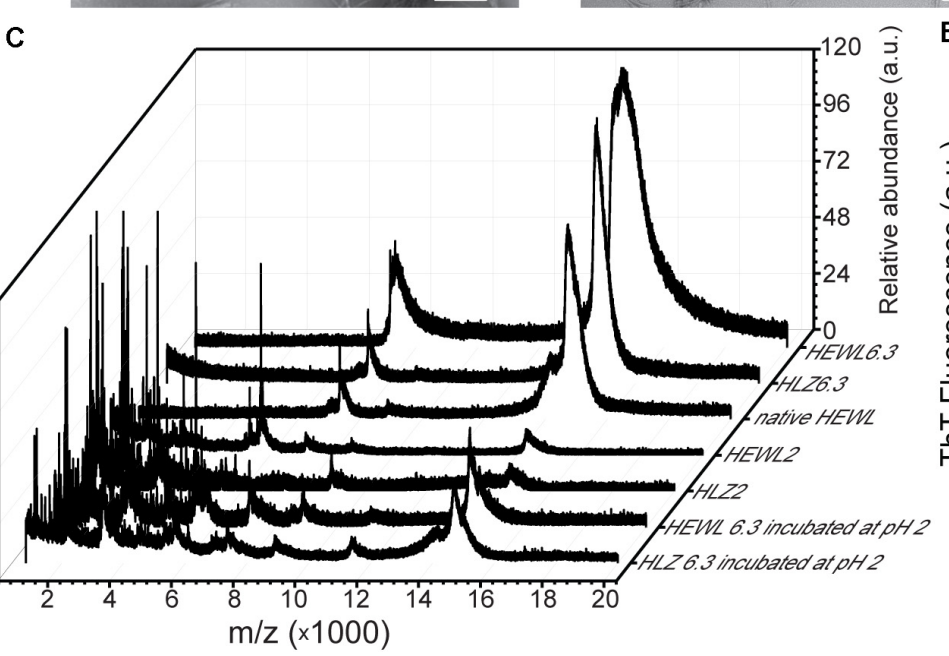

B

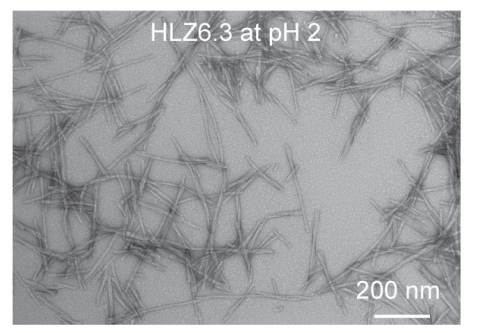

D

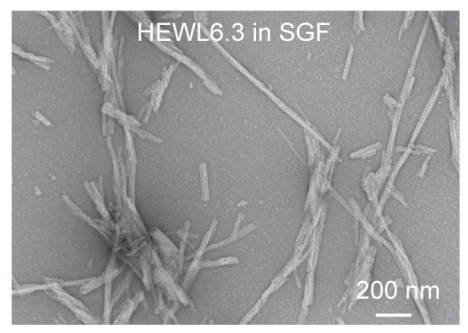

$E$

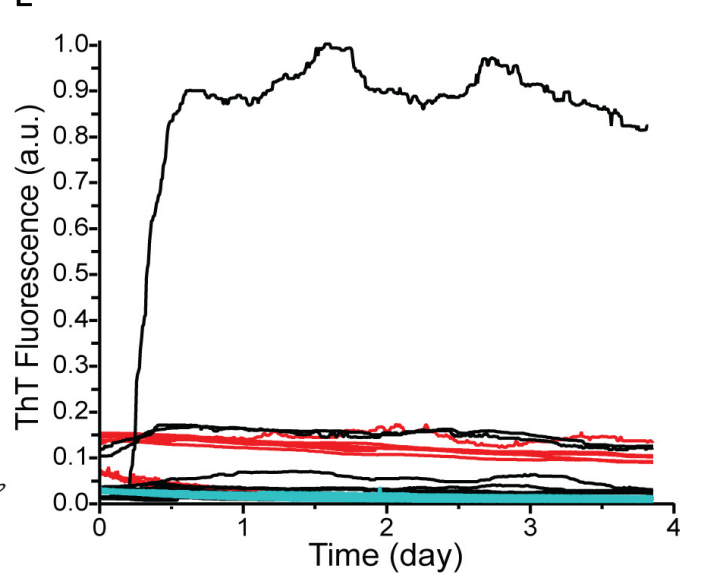

FIGURE 5 | Effect of low pH and simulated gastric fluid on fibril structure and seeding ability. TEM images of HEWL6.3 (A) and HLZ6.3 (B) after incubation for $24 \mathrm{~h}$ at $\mathrm{pH} 2,65^{\circ} \mathrm{C}$, while shaking at $300 \mathrm{rpm}$. (C) MALDI-TOF spectra for native HLZ and various fibrils. Effect of simulated gastric fluid on HEWL fibril structure (D), and on the ability of HEWL6.3 and HEWL2S to seed HLZ fibrillation (E). Native human lysozyme was incubated with HEWL fibrils in simulated gastric fluid, pH 1.2, $37^{\circ} \mathrm{C}$, containing pepsin, over nearly 4 days. Different HEWL fibril seeds were used: HEWL6.3 pre-treated with pepsin (black curves), and HEWL6.3 (red curves) and HEWL2 (cyan curves) sonicated fibrils ( $n=12$ for each seed type).

The $\mathrm{pH} 2$ fibrils are long, thin, semiflexible, and curved, while the $\mathrm{pH} 6.3$ fibrils are shorter, rigid, twisted, and associate laterally (Figure 1). These results are consistent with previous studies of lysozyme fibrils made under acidic and near-neutral $\mathrm{pH}$ conditions (Frare et al., 2004; Krebs et al., 2004; Vernaglia et al., 2004; Mossuto et al., 2010; Mocanu et al., 2014; Sulatskaya et al., 2017).

The unseeded, seeded, and cross-species seeded reactions at $\mathrm{pH} 2$ all resulted in the formation of long, unbranched, flexible fibrils (Figure 4). Conversely, seeding with the $\mathrm{pH} 6.3$ polymorphs at $\mathrm{pH} 2$ resulted in the formation of shorter, more twisted and rigid fibrils, resembling the $\mathrm{pH} 6.3$ polymorphs. This indicates that 6.3 polymorphs were dominant even at $\mathrm{pH} 2$, and the newly formed fibrils preserved the $\mathrm{pH} 6.3$ polymorph fibril structure and morphology. The faithful propagation of polymorphs under different conditions has been observed for other fibrils, including from $\mathrm{A} \beta_{1-40}$ (Petkova et al., 2005), insulin (Surmacz-Chwedoruk et al., 2012), and $\alpha$-synuclein (Peelaerts et al., 2015). Such strain fidelity can be explained on the basis of energetic barriers to fibril nucleation, as the barrier to forming a new fibril (even one of the type usually favored under the given conditions) is higher than the barrier to fibril growth; thus, it costs less energy to add a monomer to an existing fibril than to form a completely new fibril (Buell, 2019). What is interesting in this case is that the $\mathrm{pH} 6.3$ fibril polymorphs
(HLZ6.3s and HEWL6.3s) cross-seeded fibril growth at $\mathrm{pH} 2$ with rate constants nearly 10 -fold higher than unseeded fibril growth at pH 2 (Table 1).

It is not immediately clear why the $\mathrm{pH} 6.3$ polymorph grows with a faster rate constant at $\mathrm{pH} 2$ than the $\mathrm{pH} 2$ polymorph. The rate constant for fibril elongation depends both on a diffusive prefactor and a free energy barrier (i.e., $k=k_{0} \exp \left(-\Delta G^{\ddagger} / R T\right)$. The energetic barrier likely corresponds to a transition state complex formed between the fibril end and the incoming monomer (Buell, 2019). The pre-factor can be taken to arise from internal conformational dynamics of the transition state complex, which was shown to be much slower for protein misfolding than for native folding (Yu et al., 2015; Dee and Woodside, 2016). In this scenario, the $\mathrm{pH} 6.3$ and $\mathrm{pH} 2$ lysozyme polymorphs could differ in terms of their core molecular structure, such that fibril-monomer interactions are more favorable with the $\mathrm{pH} 6.3$ polymorph. While the $\mathrm{pH} 6.3$ fibrils consist of fulllength protein at $\mathrm{pH} 6.3$ (Figure 2E), incubation at $\mathrm{pH} 2$ leads to hydrolysis of surface residues leaving behind intact fibrils composed of fragmented protein (Figure 5). Nonetheless, the fibril core remains intact at $\mathrm{pH} \mathrm{2,} \mathrm{which} \mathrm{indicates} \mathrm{that} \mathrm{the}$ residues forming the fibril core, rather than regions outside the core, are what dictate the seeding and growth kinetics of the $\mathrm{pH}$ 6.3 polymorph. This is not necessarily surprising, as assembly of the fibril core would represent the largest energy barrier 
and also driving force of fibrillation (e.g., through formation of binding contacts and release of water from the buried surfaces). Hydrolysis does not preclude the self-propagation of the $\mathrm{pH}$ 6.3 polymorph at $\mathrm{pH} 2$, indicating that the $\mathrm{pH} 2$ and $\mathrm{pH}$ 6.3 fibrils can be assembled from the same pool of full-length and truncated protein, although we do not know if they share the same fibril core sequence. The molecular structures of these polymorphs might differ in several ways (Eisenberg and Sawaya, 2017): they could consist of the same core sequence folded in different topologies ("packing polymorphs"); they might consist of different segments ("segmental polymorphs"), or they may arise as a combination of different segments and packing interactions ("combinatorial polymorphs").

Fibril polymorphism, in general, arises from differences in the structure of the fibril core (molecular polymorphism) and/or differences in fibril morphology due to the protofilament arrangement (morphological or structural polymorphism) (Tycko, 2015; Adamcik and Mezzenga, 2018). Differences in the later can also have a major impact on fibril growth kinetics. For $A \beta_{1-40}$ fibrils one polymorph (ribbon-type) was dominant over another (twisted-type) during agitation, owing to it being more susceptible to shear and generating more fibril ends (Qiang et al., 2013). In our case, both polymorphs (pH 2 and $\mathrm{pH}$ 6.3) were susceptible to shear via sonication (Figures 1E,F), producing seeds on the order of $200 \mathrm{~nm}$ long. The $\mathrm{pH} 6.3$ fibrils are characteristically shorter than the $\mathrm{pH} 2$ fibrils, so it is possible that the $\mathrm{pH} 6.3$ fibrils are more brittle, undergoing breakage during shaking in the plate-reader, resulting in more fibril ends and enhanced fibril growth kinetics (Surmacz-Chwedoruk et al., 2012). An increased fragmentation rate could lead to both shorter lag-times and faster growth kinetics, as fibril growth rate is proportional to the fibril number concentration (Arosio et al., 2015). The pH 6.3 fibrils are characterized by further lateral association (Figures 1-5), which potentially affects the rates of elongation and secondary nucleation, although the details for this are not clear (Arosio et al., 2015).

We also expect to see some effect of net charge on seeding and fibril growth (Buell et al., 2013). The overall faster fibril growth kinetics at $\mathrm{pH} 6.3$ than at $\mathrm{pH} 2$ likely result from electrostatic effects. With a measured $p I$ of 11.16 , lysozyme is more positively charged $(q \sim+17)$ at $\mathrm{pH} 2$ than at $\mathrm{pH} 6.3(q \sim+8)$ (Kuehner et al., 1999), which could result in less electrostatic repulsion between the growing fibril end and incoming monomer at $\mathrm{pH}$ 6.3.

\section{Cross-Species Seeding of Lysozyme}

The kinetics of fibril growth are generally faster for HEWL than HLZ. For the unseeded reactions at $\mathrm{pH}$ 2, HEWL has nearly a four-fold shorter lag-time, yet the rate constants are similar. At pH 6.3, the lag-times are similar yet HEWL has double the growth rate constant. This suggests that, compared to HLZ, fibril nuclei formation is faster for HEWL at $\mathrm{pH} 2$ while fibril elongation is faster for HEWL at $\mathrm{pH}$ 6.3. Similarly, a previous study found that HEWL aggregates more quickly than HLZ at acidic $\mathrm{pH}$, under slightly different conditions ( $\mathrm{pH} 1.5,65^{\circ} \mathrm{C}$, with stirring), with a shorter lag-time but also a four-fold faster growth rate constant (Chaudhary et al., 2017). This general trend held up across the different seeding and cross-seeding samples examined here, where HEWL aggregation was faster in terms of lag-times and/or rate constants. Although HEWL aggregation was overall faster, trends in the effectiveness of the different fibrils (species and polymorph type) to act as seeds were more nuanced.

The molecular and morphological factors that underly crossseeding are not well-understood, yet cross-seeding is generally inefficient for proteins of low sequence similarity (Tycko, 2015). This is not an absolute relationship, as similar proteins like $\mathrm{A} \beta_{1-40}$ and $\mathrm{A} \beta_{1-42}$ fibrils do not cross-seed efficiently (Lu et al., 2013) while different proteins such as $\alpha$-synuclein and tau fibrils do cross-seed each other (Giasson et al., 2003). We found that lysozyme from human and hen, with $60 \%$ sequence identity, cross-seeded each other under both conditions $(\mathrm{pH} 2, \mathrm{pH} 6.3)$ with differing efficiencies. HEWL2 ${ }_{S}$ reduced the lag-time of HLZ2 by a factor of four, while HLZ2 $\mathrm{S}$ was a poor seed and cross-seed, leading to only a small drop in the lag-time (less than two-fold reduction) for both human and hen lysozyme at $\mathrm{pH} 2$. This result is consistent with the findings of Krebs et al. (2004), who found that HLZ fibrils prepared at $\mathrm{pH} 2,65^{\circ} \mathrm{C}$, reduced the lag-time for HEWL from around 2.5 days (unseeded) to 1.5 days (crossseeded). Conversely, under the $\mathrm{pH} 6.3$ condition, HEWL6.3 $\mathrm{S}$ had minimal effect on the lag-time of HLZ6.3, while HLZ6.3s reduced the lag-time of HEWL6.3 by nearly three-fold (Table 1).

\section{Seeding Under Mild (Non-denaturing) Conditions}

Previous studies have shown that HEWL fibrils are unable to seed fibril formation under mild or non-denaturing conditions (e.g., without $\mathrm{GdnHCl}$ or low $\mathrm{pH}$ with high temperature). Fibril seeds made at $\mathrm{pH} 6.3,3 \mathrm{M} \mathrm{GdnHCl}, 50^{\circ} \mathrm{C}$, were unable to seed fibril formation at $45^{\circ} \mathrm{C}$ without $3 \mathrm{M} \mathrm{GdnHCl}$, but did so with denaturant present (Vernaglia et al., 2004). HEWL fibrils made at $\mathrm{pH} 3$ could not seed fibrillation within $48 \mathrm{~h}$ at $\mathrm{pH} 3,37^{\circ} \mathrm{C}$, or within $72 \mathrm{~h}$ at $\mathrm{pH} 7,37^{\circ} \mathrm{C}$ (Mulaj et al., 2014). Here, we looked for HEWL6.3 $\mathrm{S}$ cross-seeding of HLZ under simulated gastric conditions (pepsin, $\mathrm{pH} 1.2,34 \mathrm{mM} \mathrm{NaCl}, 37^{\circ} \mathrm{C}$ ) and found that only one out of 36 samples showed signs of amyloid formation after 4 days (Figure 5E). Such a low propensity for amyloid fibril formation, even in the presence of fibril seeds, might be expected when the solution conditions are well below the equilibrium denaturation mid-point (Buell et al., 2011). The $T_{\mathrm{m}}$ for HEWL is approximately $45^{\circ} \mathrm{C}$ at $\mathrm{pH} 1$, and $50^{\circ} \mathrm{C}$ at $\mathrm{pH} 2$, while the $T_{\mathrm{m}}$ for $\mathrm{HLZ}$ is around $52^{\circ} \mathrm{C}$ at $\mathrm{pH} 2$ and $80^{\circ} \mathrm{C}$ at $\mathrm{pH}$ 6 (Trexler and Nilsson, 2007). At $\mathrm{pH} 6.3,50^{\circ} \mathrm{C}$, the denaturant mid-point for $\mathrm{HEWL}$ is around $2.5 \mathrm{M} \mathrm{GdnHCl}$, and the protein is $80 \%$ denatured at $3 \mathrm{M} \mathrm{GdnHCl}$ (Vernaglia et al., 2004). Without sufficient destabilizing conditions, the proteins do not readily aggregate into fibrils. Overly denaturing conditions also disfavor fibrillation (Vernaglia et al., 2004). In the absence of denaturant, pepsin treatment might lead to partial digestion and release of fibril-forming fragments. While HEWL is resistant to pepsin, HLZ is more susceptible (Polverino de Laureto et al., 2002; Frare et al., 2006). Yet, even with pepsin, we observed a low, but non-zero, propensity for fibrillation. These results indicate that, in the absence of more destabilizing conditions, cross-seeding is quite rare. However, these results also lend support to the 
notion that fibril growth kinetics can be highly sensitive to the particular environmental conditions and the identity of the seeds and monomeric protein.

The issue of cross-seeding is relevant to assessing the safety of engineered amyloid for various technology applications (Knowles and Mezzenga, 2016), particularly in food (Solomon et al., 2007; Raynes et al., 2014; Lasse et al., 2016). While fibrils made from various milk, egg, and legume proteins showed no evidence of cell toxicity (Lasse et al., 2016), further studies are required that address cross-seeding along with cell toxicity. Different polymorphs should be examined, as some may be toxic while others are not (Mossuto et al., 2010). Our results highlight that certain polymorphs, or strains, are more proficient in seeding, even under conditions that differ from which they were formed. This cross-species-cross-polymorph seeding should be considered when assessing the safety of engineered fibrils.

These results further indicate that polymorphism and strain fidelity is a unique feature of fibrils that could be utilized when creating fibril-based materials. Fibrils with desired properties can be formed under one set of conditions $(\mathrm{pH}$, temperature, ionic strength, chaotropes) and then used as seeds to scale production

\section{REFERENCES}

Adamcik, J., and Mezzenga, R. (2018). Amyloid polymorphism in the protein folding and aggregation energy landscape. Angew. Chem. Int. Ed. Engl. 57, 8370-8382. doi: 10.1002/anie.201713416

Annamalai, K., Gührs, K., Koehler, R., Schmidt, M., Michel, H., Loos, C., et al. (2016). Polymorphism of amyloid fibrils in vivo. Angew. Chem. Int. Ed. Engl. 55, 4822-4825. doi: 10.1002/anie.201511524

Arnaudov, L. N., and de Vries, R. (2005). Thermally induced fibrillar aggregation of hen egg white lysozyme. Biophys. J. 88, 515-526. doi: 10.1529/biophysj.104. 048819

Arosio, P., Knowles, T. P. J., and Linse, S. (2015). On the lag phase in amyloid fibril formation. Phys. Chem. Chem. Phys. 17, 7606-7618. doi: 10.1039/c4cp0 $5563 \mathrm{~b}$

Bousset, L., Pieri, L., Ruiz-Arlandis, G., Gath, J., Jensen, P. H., Habenstein, B., et al. (2013). Structural and functional characterization of two alpha-synuclein strains. Nat. Commun. 4:2575. doi: 10.1038/ncomms3575

Buell, A. K. (2019). The growth of amyloid fibrils: rates and mechanisms. Biochem. J. 476, 2677-2703. doi: 10.1042/BCJ20160868

Buell, A. K., Dhulesia, A., Mossuto, M. F., Cremades, N., Kumita, J. R., Dumoulin, M., et al. (2011). Population of nonnative states of lysozyme variants drives amyloid fibril formation. J. Am. Chem. Soc. 133, 7737-7743. doi: 10.1021/ ja109620d

Buell, A. K., Hung, P., Salvatella, X., Welland, M. E., Dobson, C. M., and Knowles, T. P. J. (2013). Electrostatic effects in filamentous protein aggregation. Biophys. J. 104, 1116-1126. doi: 10.1016/j.bpj.2013.01.031

Chaudhary, A. P., Vispute, N. H., Shukla, V. K., and Ahmad, B. (2017). A comparative study of fibrillation kinetics of two homologous proteins under identical solution condition. Biochimie 132, 75-84. doi: 10.1016/j.biochi.2016. 11.002

Chiti, F., and Dobson, C. M. (2017). Protein misfolding, amyloid formation, and human disease: a summary of progress over the last decade. Annu. Rev. Biochem. 86, 27-68. doi: 10.1146/annurev-biochem-061516-045115

Cobb, N. J., Apostol, M. I., Chen, S., Smirnovas, V., and Surewicz, W. K. (2014). Conformational stability of mammalian prion protein amyloid fibrils is dictated by a packing polymorphism within the core region. J. Biol. Chem. 289, 26432650. doi: $10.1074 /$ jbc.M113.520718

Collinge, J., and Clarke, A. R. (2007). A general model of prion strains and their pathogenicity. Science 318, 930-936. doi: 10.1126/science.1138718 of identical fibrils under a different set of conditions, which may offer downstream advantages.

\section{DATA AVAILABILITY STATEMENT}

The raw data supporting the conclusions of this article will be made available by the authors, without undue reservation.

\section{AUTHOR CONTRIBUTIONS}

Both authors designed the research, analyzed the data, and wrote the manuscript. LR performed the experiments.

\section{FUNDING}

Funding for this research was provided by the Georgia Agricultural Experiment Station, University of Georgia, and publication fees were paid with funds from The University of British Columbia.

Dee, D. R., and Woodside, M. T. (2016). Comparing the energy landscapes for native folding and aggregation of PrP. Prion 10, 207-220. doi: 10.1080/ 19336896.2016.1173297

Eisenberg, D. S., and Sawaya, M. R. (2017). Structural studies of amyloid proteins at the molecular level. Annu. Rev. Biochem. 86, 3.1-3.27.

Fowler, D. M., Koulov, A. V., Balch, W. E., and Kelly, J. W. (2007). Functional amyloid-from bacteria to humans. Trends Biochem. Sci. 32, 217-224. doi: 10.1016/j.tibs.2007.03.003

Frare, E., Mossuto, M. F., Polverino, de Laureto, P., Dumoulin, M., Dobson, C. M., et al. (2006). Identification of the core structure of lysozyme amyloid fibrils by proteolysis. J. Mol. Biol. 361, 551-561. doi: 10.1016/j.jmb.2006.06.055

Frare, E., Polverino, de Laureto, P., Zurdo, J., Dobson, C. M., and Fontana, A. (2004). A highly amyloidogenic region of hen lysozyme. J. Mol. Biol. 340, 1153-1165. doi: 10.1016/j.jmb.2004.05.056

Friedland, R. P., and Chapman, M. R. (2017). The role of microbial amyloid in neurodegeneration. PLoS Pathog. 13:e1006654. doi: 10.1371/journal.ppat. 1006654

Giasson, B. I., Forman, M. S., Higuchi, M., Golbe, L. I., Graves, C. L., Kotzbauer, P. T., et al. (2003). Initiation and synergistic fibrillization of tau and alphasynuclein. Science 300, 636-640. doi: 10.1126/science.1082324

Hartman, K., Brender, J. R., Monde, K., Ono, A., Evans, M. L., Popovych, N., et al. (2013). Bacterial curli protein promotes the conversion of PAP248-286 into the amyloid SEVI: cross-seeding of dissimilar amyloid sequences. PeerJ. 1:e5. doi: $10.7717 /$ peerj. 5

Hashimoto, M., Ho, G., Takamatsu, Y., Wada, R., Sugama, S., Takenouchi, T., et al. (2019). Possible role of amyloid cross-seeding in evolvability and neurodegenerative disease. J Parkinsons Dis. 9, 793-802. doi: 10.3233/JPD191675

Jarrett, J. T., and Lansbury, P. T. (1993). Seeding "one-dimensional crystallization" of amyloid: a pathogenic mechanism in Alzheimer's disease and scrapie? Cell 73, 1055-1058. doi: 10.1016/0092-8674(93)90635-4

Knowles, T. P., and Mezzenga, R. (2016). Amyloid fibrils as building blocks for natural and artificial functional materials. Adv. Mater. 28, 6546-6561. doi: 10. 1002/adma.201505961

Krebs, M. R., Morozova-Roche, L. A., Daniel, K., Robinson, C. V., and Dobson, C. M. (2004). Observation of sequence specificity in the seeding of protein amyloid fibrils. Protein Sci. 13, 1933-1938. doi: 10.1110/ps.04707004

Krebs, M. R., Wilkins, D. K., Chung, E. W., Pitkeathly, M. C., Chamberlain, A. K., Zurdo, J., et al. (2000). Formation and seeding of amyloid fibrils from wild-type 
hen lysozyme and a peptide fragment from the beta-domain. J. Mol. Biol. 300, 541-549. doi: 10.1006/jmbi.2000.3862

Kuehner, D. E., Engmann, J., Fergg, F., Wernick, M., Blanch, H. W., and Prausnitz, J. M. (1999). Lysozyme net charge and ion binding in concentrated aqueous electrolyte solutions. J. Phys. Chem. B 103, 1368-1374. doi: 10.1021/jp983852i

Lara, C., Adamcik, J., Jordens, S., and Mezzenga, R. (2011). General self-assembly mechanism converting hydrolyzed globular proteins into giant multistranded amyloid ribbons. Biomacromolecules 12, 1868-1875. doi: 10.1021/bm200216u

Lasse, M., Ulluwishewa, D., Healy, J., Thompson, D., Miller, A., Roy, N., et al. (2016). Evaluation of protease resistance and toxicity of amyloid-like food fibrils from whey, soy, kidney bean, and egg white. Food Chem. 192, 491-498. doi: 10.1016/j.foodchem.2015.07.044

Liu, X., Liang, C., Zhang, X., Li, J., Huang, J., Zeng, L., et al. (2017). Amyloid fibril aggregation: an insight into the underwater adhesion of barnacle cement. Biochem. Biophys. Res. Commun. 493, 654-659. doi: 10.1016/j.bbrc.2017.08.136

Loveday, S. M., Rao, M. A., Creamer, L. K., and Singh, H. (2009). Factors affecting rheological characteristics of fibril gels: the case of beta-lactoglobulin and alpha-lactalbumin. J. Food Sci. 74, R47-R55.

Lu, J., Qiang, W., Yau, W., Schwieters, C. D., Meredith, S. C., and Tycko, R. (2013). Molecular structure of $\beta$-amyloid fibrils in Alzheimer's disease brain tissue. Cell 154, 1257-1268. doi: 10.1016/j.cell.2013.08.035

Maji, S. K., Perrin, M. H., Sawaya, M. R., Jessberger, S., Vadodaria, K., Rissman, R. A., et al. (2009). Functional amyloids as natural storage of peptide hormones in pituitary secretory granules. Science 325, 328-332. doi: 10.1126/science. 1173155

Mocanu, M., Ganea, C., Siposova, K., Filippi, A., Demjen, E., Marek, J., et al. (2014). Polymorphism of hen egg white lysozyme amyloid fibrils influences the cytotoxicity in LLC-PK1 epithelial kidney cells. Int. J. Biol. Macromol. 65, 176-187. doi: 10.1016/j.ijbiomac.2014.01.030

Mohammadian, M., and Madadlou, A. (2018). Technological functionality and biological properties of food protein nanofibrils formed by heating at acidic condition. Trends Food Sci. Technol. 75, 115-128. doi: 10.1016/j.tifs.2018.0 3.013

Morales, R., Moreno-Gonzalez, I., and Soto, C. (2013). Cross-seeding of misfolded proteins: implications for etiology and pathogenesis of protein misfolding diseases. PLoS Pathog. 9:e1003537. doi: 10.1371/journal.ppat.1003537

Mossuto, M. F., Dhulesia, A., Devlin, G., Frare, E., Kumita, J. R., de Laureto, P. P., et al. (2010). The non-core regions of human lysozyme amyloid fibrils influence cytotoxicity. J. Mol. Biol. 402, 783-796. doi: 10.1016/j.jmb.2010.07.005

Mulaj, M., Foley, J., and Muschol, M. (2014). Amyloid oligomers and protofibrils, but not filaments, self-replicate from native lysozyme. J. Am. Chem. Soc. 136, 8947-8956. doi: 10.1021/ja502529m

Pace, C. N. (1986). Determination and analysis of urea and guanidine hydrochloride denaturation curves. Meth. Enzymol. 131, 266-280. doi: 10.1016/ 0076-6879(86)31045-0

Peelaerts, W., Bousset, L., Van der Perren, A., Moskalyuk, A., Pulizzi, R., Giugliano, M., et al. (2015). $\alpha$-Synuclein strains cause distinct synucleinopathies after local and systemic administration. Nature 522, 340-344. doi: 10.1038/nature14547

Pellarin, R., Schuetz, P., Guarnera, E., and Caflisch, A. (2010). Amyloid fibril polymorphism is under kinetic control. J. Am. Chem. Soc. 132, 14960-14970. doi: $10.1021 / \mathrm{ja} 106044 \mathrm{u}$

Petkova, A. T., Leapman, R. D., Guo, Z., Yau, W., Mattson, M. P., and Tycko, R. (2005). Self-propagating, molecular-level polymorphism in Alzheimer's betaamyloid fibrils. Science 307, 262-265. doi: 10.1126/science.1105850

Polverino de Laureto, P., Frare, E., Gottardo, R., Van Dael, H., and Fontana, A. (2002). Partly folded states of members of the lysozyme/lactalbumin superfamily: a comparative study by circular dichroism spectroscopy and limited proteolysis. Protein Sci. 11, 2932-2946. doi: 10.1110/ps.0205802
Qiang, W., Kelley, K., and Tycko, R. (2013). Polymorph-specific kinetics and thermodynamics of $\beta$-amyloid fibril growth. J. Am. Chem. Soc. 135, 6860-6871. doi: $10.1021 / \mathrm{ja} 311963 \mathrm{f}$

Raynes, J. K., Carver, J. A., Gras, S. L., and Gerrard, J. A. (2014). Protein nanostructures in food-should we be worried? Trends Food Sci. Technol. 37, 42-50. doi: 10.1016/j.tifs.2014.02.003

Sneideris, T., Darguzis, D., Botyriute, A., Grigaliunas, M., Winter, R., and Smirnovas, V. (2015). pH-driven polymorphism of insulin amyloid-like fibrils. PLoS One 10:e136602. doi: 10.1371/journal.pone. 0136602

Solomon, A., Richey, T., Murphy, C. L., Weiss, D. T., Wall, J. S., Westermark, G. T., et al. (2007). Amyloidogenic potential of foie gras. Proc. Natl. Acad. Sci. U. S. A. 104, 10998-11001. doi: 10.1073/pnas.0700848104

Stephens, A. D., and Kaminski Schierle, G. S. (2019). The role of water in amyloid aggregation kinetics. Curr. Opin. Struct. Biol. 58, 115-123. doi: 10.1016/j.sbi. 2019.06.001

Sulatskaya, A. I., Rodina, N. P., Povarova, O. I., Kuznetsova, I. M., and Turoverov, K. K. (2017). Different conditions of fibrillogenesis cause polymorphism of lysozyme amyloid fibrils. J. Mol. Struct. 1140, 52-58. doi: 10.1016/j.molstruc. 2016.10.037

Surmacz-Chwedoruk, W., Nieznańska, H., Wójcik, S., and Dzwolak, W. (2012). Cross-seeding of fibrils from two types of insulin induces new amyloid strains. Biochemistry 51, 9460-9469. doi: 10.1021/bi301144d

Swaminathan, R., Ravi, V. K., Kumar, S., Kumar, M. V., and Chandra, N. (2011). Lysozyme: a model protein for amyloid research. Adv. Protein Chem. Struct. Biol. 84, 63-111.

Trexler, A. J., and Nilsson, M. R. (2007). The formation of amyloid fibrils from proteins in the lysozyme family. Curr. Protein Pept. Sci. 8, 537-557. doi: 10. 2174/138920307783018659

Tycko, R. (2015). Amyloid polymorphism: structural basis and neurobiological relevance. Neuron 86, 632-645. doi: 10.1016/j.neuron.2015.03.017

Usov, I., Adamcik, J., and Mezzenga, R. (2013). Polymorphism complexity and handedness inversion in serum albumin amyloid fibrils. ACS Nano 7, 1046510474. doi: $10.1021 / \mathrm{nn} 404886 \mathrm{k}$

Vernaglia, B. A., Huang, J., and Clark, E. D. (2004). Guanidine hydrochloride can induce amyloid fibril formation from hen egg-white lysozyme. Biomacromolecules 5, 1362-1370. doi: 10.1021/bm0498979

Wright, C. F., Teichmann, S. A., Clarke, J., and Dobson, C. M. (2005). The importance of sequence diversity in the aggregation and evolution of proteins. Nature 438, 878-881. doi: 10.1038/nature04195

Yu, H., Dee, D. R., Liu, X., Brigley, A. M., Sosova, I., and Woodside, M. T. (2015). Protein misfolding occurs by slow diffusion across multiple barriers in a rough energy landscape. Proc. Natl. Acad. Sci. U. S. A. 112, 8308-8313. doi: 10.1073/pnas.1419197112

Zhang, M., Hu, R., Chen, H., Chang, Y., Ma, J., Liang, G., et al. (2015). Polymorphic cross-seeding amyloid assemblies of amyloid- $\beta$ and human islet amyloid polypeptide. Phys. Chem. Chem. Phys. 17, 23245-23256. doi: 10.1039/ c5cp03329b

Conflict of Interest: The authors declare that the research was conducted in the absence of any commercial or financial relationships that could be construed as a potential conflict of interest.

Copyright $\odot 2020$ Rahimi Araghi and Dee. This is an open-access article distributed under the terms of the Creative Commons Attribution License (CC BY). The use, distribution or reproduction in other forums is permitted, provided the original author(s) and the copyright owner(s) are credited and that the original publication in this journal is cited, in accordance with accepted academic practice. No use, distribution or reproduction is permitted which does not comply with these terms. 